2008

\title{
A sex difference in seasonal timing of birth in a livebearing fish
}

Eric T. Schultz

University of Connecticut - Storrs, eric.schultz@uconn.edu

Follow this and additional works at: https://opencommons.uconn.edu/eeb_articles

Part of the Evolution Commons, Population Biology Commons, and the Terrestrial and Aquatic Ecology Commons

\section{Recommended Citation}

Schultz, Eric T., "A sex difference in seasonal timing of birth in a livebearing fish" (2008). EEB Articles. 13.

https://opencommons.uconn.edu/eeb_articles/13 


\title{
A Sex Difference in Seasonal Timing of Birth in a Livebearing Fish
}

\author{
Eric T. Schultz ${ }^{1}$
}

\begin{abstract}
Sex differences in seasonal timing include differences in hatch- or birth-date distribution and differences in the timing of migration or maturation such as protandrous arrival timing (PAT), which is early male arrival at breeding sites. I describe a novel form of protandrous arrival timing, as a sex difference in birth-date distribution in a live-bearing fish (Dwarf Perch, Micrometrus minimus). In this species, birth coincides with arrival at breeding sites because newborn males are sexually active. A series of samples of pregnant females and young of year was collected in Tomales Bay, CA. I analyzed the daily age record in otoliths to estimate the conception date of broods and the age that young-of-year individuals were born. Males were born at a younger age than females, as indicated by the daily age record and also by the predominance of females in broods from which some young had already been born, which was a common occurrence in pregnant females with older embryos. Sex ratio of broods varied with conception date such that early-season broods were predominantly male, possibly as a result of temperature-dependent sex determination. The combined effects of the sex difference in age at birth and seasonal shift in sex ratio were to shift the mean birth date of males relative to females by five days. The most likely ultimate explanation for PAT in the Dwarf Perch is that it arises from exploitation (scramble) competition for mating opportunities among recently-born young-of-year males.
\end{abstract}

$\mathrm{S}$ EXUAL differences in the seasonal timing of life history transitions and behavior arise in response to natural and sexual selection. Sex differences in the seasonal timing of birth are widespread. For example, sex differences in hatch date distribution have been shown in two ectothermic vertebrates in which there is temperaturedependent sex determination (TSD; Harlow and Taylor, 2000; Conover, 2004). Similarly, the sex ratio of offspring varies with season in some birds and mammals (Dijkstra et al., 1990; Wright et al., 1995; Daan et al., 1996; Smallwood and Smallwood, 1998). Another well-documented pattern of sexual difference in seasonal timing is protandrous arrival timing (PAT, not to be confused with protandry as a form of sequential hermaphroditism), which is early male arrival at breeding sites because of sex differences in the timing of migration or transition to adulthood. Such sex differences in the timing of migration have been documented in various vertebrates (Kokko, 1999; Morbey, 2002); relatively early male metamorphosis and emergence from diapause is widespread in the Arthropoda (Thornhill and Alcock, 1983).

In this paper, I describe a novel form of PAT in a livebearing fish (Dwarf Perch, Micrometrus minimus). In this species, birth coincides with arrival at breeding sites because newborn males are sexually active. After a roughly threemonth gestation period (Schultz, 1990a) during which testes develop in male embryos (Schultz, 1993a), males are born mature (Hubbs, 1921; Warner and Harlan, 1982). Newborn males (but not prenatal males) court and inseminate females, possibly for four weeks after birth (Schultz and Rountos, 2001). Young-of-year (YOY) females are not yet mature, storing sperm until fertilization in the following winter. The initial observation that early-born individuals were predominantly male stimulated the analyses presented here, which were designed to test for PAT as a sex difference in the distribution of birth dates and test two potential contributors to PAT, sex differences in age at birth and change in brood sex ratio with date of conception. An additional objective of this paper is to identify adaptive explanations for PAT that are most likely in this species, and to suggest testable predictions. Multiple hypotheses have been advanced for PAT's ultimate function (Morbey and Ydenberg, 2001), invoking the action of natural and sexual selection.

\section{MATERIALS AND METHODS}

Specimen capture and workup.-Samples were collected in grassbeds (Zostera marina) in Tomales Bay, CA. Details of sampling and workup are provided in Schultz (1990b). Most samples were of the 1986 yearclass. Sampling of pregnant females and subsequent YOY commenced in early March 1986 and continued on a biweekly schedule through June 1986 , at which time all females had given birth. Sampling of YOY individuals continued at monthly intervals until the early autumn. Additional samples of pregnant females were taken from late February to late June 1987. Sample size for pregnant females was 552 in 1986 and 233 in 1987. Pregnant females were bagged individually, placed on ice, and dissected within 12 hours to recover embryos. Specimens were preserved in $95 \%$ ethanol.

Pregnant females were scored for whether parturition was imminent or underway during the workup, to distinguish preparturient broods (i.e., not sufficiently developed to be born) and parturient broods (from which some embryos may have already been born). A brood was scored as parturient if the female had a partially everted ovary reflecting recent parturition (Hubbs, 1917). Eversion may have occurred after capture and bagging, therefore some broods that were scored as parturient may have been complete.

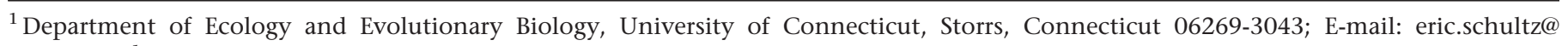
uconn.edu.

Submitted: 8 August 2007. Accepted: 20 January 2008. Associate Editor: S. A. Schaefer.

(c) 2008 by the American Society of Ichthyologists and Herpetologists DOI: 10.1643/CE-07-168
} 
Table 1. Preparturient Brood Size as a Function of Female Size and Age. Analysis of covariance (results not shown) indicated significant difference in fecundity with age. For each female age class, table entries are mean length in mm (SE), mean fecundity (SE), and statistics of log-log regression of embryo number against length: intercept (SE), slope (SE), and adjusted R². P-values for each regression estimate are $\leq 0.01$.

\begin{tabular}{ccccc}
\hline & Mean length & Mean fecundity & Intercept & Slope \\
\hline $\begin{array}{l}1986 \text { broods } \\
\text { Age 1 }\end{array}$ & $72(2.0)$ & $12(1.0)$ & $-4.0(0.63)$ & $1.5(0.15)$ \\
Age 2 & $93(0.46)$ & $23(0.33)$ & $-4.2(0.96)$ & $1.6(0.21)$ \\
$\begin{array}{l}1987 \text { broods } \\
\text { Age 1 }\end{array}$ & $77(0.38)$ & $14(0.26)$ & $-3.4(1.2)$ & 0.24 \\
Age 2 & $94(0.55)$ & $22(0.54)$ & $-4.3(1.7)$ & $1.4(0.29)$ \\
\hline
\end{tabular}

Data collected.-The data collected on pregnant females and their broods included maternal age in years, the number of embryos in a brood, brood sex ratio, and embryo age in days. The age of pregnant females (one or two years) was based on modes in length-frequency distributions, supplemented by examinations of scales (Schultz, 1990b, 1993b). Brood sex ratio can be determined for most broods, because a thickening of the anal fin that signifies development of male sexual characters appears once the embryos are approximately $13 \mathrm{~mm}$ standard length (SL, about 30 days after conception; Schultz, 1990a). Embryo age was estimated from mean embryo size in a brood, based on previous analysis of daily age from otolith (earstone) microstructure and size-age relationships (Schultz, 1990a). Embryos in a brood do not differ in age (Schultz, 1990a). Embryo age analysis was conducted only on broods in 1986.

The data collected from YOY individuals included age at birth and date of birth. The otolith daily age record contains a birth mark (Schultz, 1990a). Using established procedures for extraction and examination of otoliths (Schultz, 1990a), I counted the daily growth increments that formed before the birth mark to estimate age at birth.

Statistical analyses.-I conducted statistical tests for two factors that could contribute to PAT, and estimated and tested for PAT. Multiple approaches were used when possible to ensure that estimates were accurate and inferences were valid. One potential contributor to PAT is a sex difference in age at birth, i.e., males should be born earlier in development than females. I used two independent approaches to test this prediction (see below). Another potential contributor to PAT is a seasonal change in brood sex ratio, such that early broods should be predominantly male. I estimated PAT, the amount to which male birth-date distributions are shifted relative to female birth-date distributions, and conducted tests of whether there is a significant difference between the distributions, using two independent approaches to estimate sex-specific birth-date distributions.

One test of sex differences in age at birth was to determine whether there was a sex ratio bias in broods from which some embryos had already been born. If males were born at an earlier age than females, then parturient broods from which some embryos had already been born should be predominantly female. The number of embryos that were missing from parturient broods was estimated as residual fecundity, i.e., observed fecundity minus expected fecundity. Expected fecundity was predicted from maternal length, based on log-log linear regressions of fecundity vs. length among preparturient broods, conducted separately for each maternal age (Table 1). Values for expected fecundity were corrected for estimation bias arising from back-transformation of $\log _{10}$ regression (Newman, 1993). The relationship between brood sex ratio and residual fecundity was tested as a correlation; I analyzed the relationship for both partial broods and full broods.

Another test of sex differences in age at birth used YOY individuals. Data on age at birth (originally presented in Schultz, 1990a) were reanalyzed for a sex difference in the number of pre-birth daily growth increments on otoliths, as expected if males are born at an earlier age than females. This was conducted via a two-sample t-test.

Seasonal change in brood sex ratio was tested by estimating the dependence of brood sex ratio on the timing of its conception. The date of conception was estimated as the difference between collection date and embryo age, determined in 1986 yearclass broods as described above. The relationship between sex ratio (as proportion of brood that is male, arcsine transformed) and birth date was tested as a correlation, using preparturient broods.

I developed two independent estimates of PAT (for details see Appendix 1 and Schultz, 1993b) for the 1986 yearclass. The first analysis employed a "prospective" estimate of birth-date distributions based on embryos. Because a sex difference in age at birth was assumed in this estimation procedure, no significance test of the sex difference in the prospective birth-date distributions was conducted. The second estimate of birth-date distributions was a "retrospective" estimate based on YOY. The difference between male and female birth-date distributions was tested via a onetailed Kolmogorov-Smirnov two-sample test (chi-square approximation for large samples; Siegel and Castellan, 1988), for which birth dates were classified into week-long intervals.

\section{RESULTS}

Brood sex ratio and ontogeny.-Broods from which some young had already been released were a common occurrence in pregnant females with older embryos. Parturient broods were collected in May and June, but not earlier in the spring. In early May of 1986, parturient broods were $7 \%$ of the broods collected, then increased in frequency to $41 \%$ and $62 \%$ of brood collected in early and late June, respectively. In early May through June of 1987, the incidence of parturient broods increased from $25 \%$ to $100 \%$ of broods collected. Overall, parturient broods were 20\% (162 of 785) of all broods that were old enough to be evaluated for sex ratio.

Some but not all parturient broods had fewer than expected embryos. Some parturient broods had more 
A

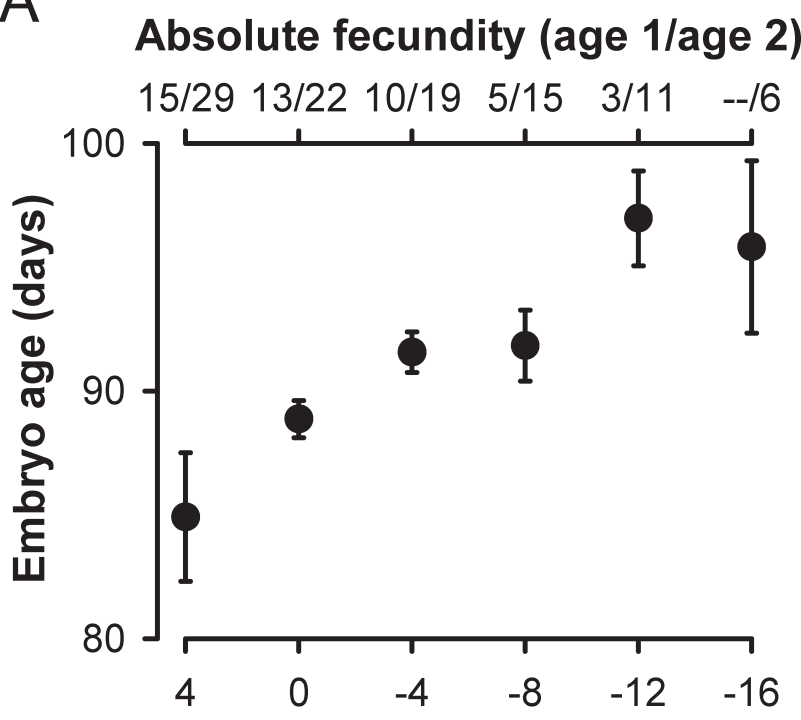

B

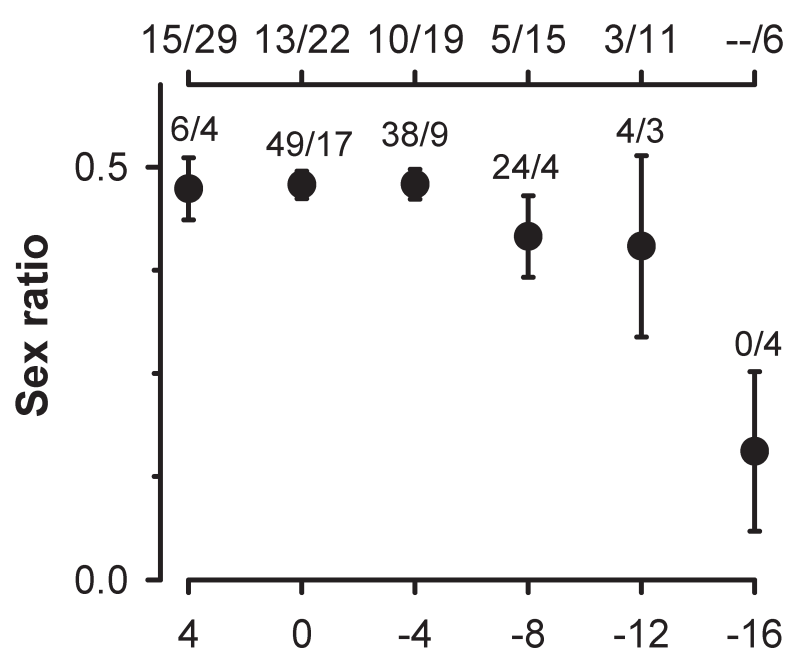

\section{Residual fecundity (observed-expected)}

Fig. 1. The embryo age and sex ratio of parturient broods. (A) Mean embryo age $( \pm \mathrm{SE})$ against residual fecundity and absolute fecundity. The lower $\mathrm{X}$-axis is residual fecundity (difference between observed and predicted number of embryos in the brood, in 4-embryo classes; see text for explanation); because residual fecundity decreases when a portion of the brood is born and a portion is retained, the X-axis is reversed. The upper $X$-axis represents mean absolute fecundity for each residual fecundity class, reported separately for each female age class as age 1/age 2. (B) Mean sex ratio against residual fecundity and absolute fecundity. $X$-axes constructed as in (A). Sex ratio is plotted as proportion of the brood that is male ( \pm SE). Sample size is indicated for each data point, reported separately for each female age class as age 1/age 2 .

embryos than the mean number for females of that size (i.e., positive residual fecundity). Evidence that some embryos had been born from parturient broods was the negative mean residual fecundity of parturient broods (mean: -3.3 embryos, $\mathrm{SE}=0.35$ ).

Consistent with the prediction that males are born earlier in development than females, parturient broods from which some embryos had been born were female-biased. Parturient broods with a greater shortfall in embryos (more negative residual fecundity) had older embryos, indicating that

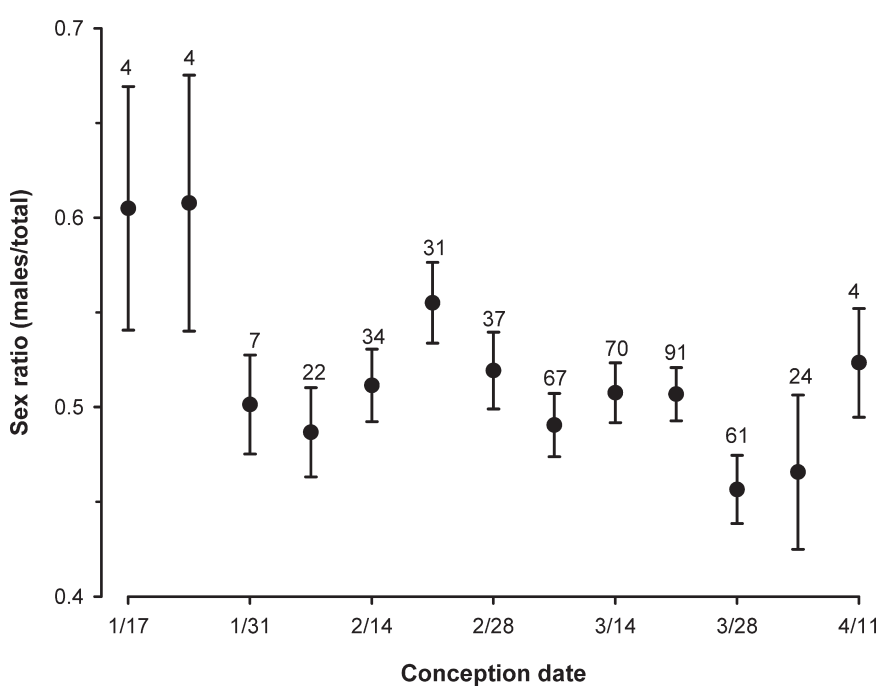

Fig. 2. Brood sex ratio and conception date. Mean sex ratio ( $\pm S E$ ) is plotted against conception date in seven-day classes. Sample size is indicated for each sex ratio data point.

negative residual fecundity is associated with retention of more developed embryos (Fig. $1 \mathrm{~A} ; \mathrm{R}=-0.37, P<0.0001$ ). There was a correlation between brood sex ratio and residual fecundity among parturient broods (Fig. 1B: $\mathrm{R}=0.32, P<$ $0.0001)$, but not preparturient broods $(P=0.98)$.

An independent indication that males were born at a younger age than females is that there were fewer daily increments prior to the birth mark in the otoliths of YOY males than in the otoliths of YOY females (female: mean $=$ $90, n=30, \mathrm{SE}=1.5$; male: mean $=86, n=33, \mathrm{SE}=1.0)$. The difference between the sexes in age at birth was significant (one-tailed t-test, $\mathrm{t}=2.2, P=0.014$ ).

Brood sex ratio and conception date.-Consistent with the prediction that brood sex ratio changes with conception date, early-season broods were male-biased. The earliest broods, conceived in mid-January, were on average $60 \%$ male (Fig. 2). The latest broods were conceived in mid April. While the average brood sex ratio was less than $50 \%$ male among broods conceived in late March and early April, the two latest broods conceived on 12 April and 22 April were $58 \%$ and $75 \%$ male, respectively. Overall, there was a significant relationship between sex ratio and conception date $(\mathrm{R}=-0.12, P=0.008)$. This relationship is strongly influenced but not entirely dependent on the mid-January broods (correlation after eliminating eight earliest broods: $\mathrm{R}$ $=-0.092, P=0.052)$.

Sex differences in birth date.-Male and female birth-date distributions broadly overlapped but differed as predicted; PAT was observed. Births took place over a three-month period with a peak in late May. While male and female births occurred on virtually all dates within this period, there were nonetheless differences between male and female birth-date distributions. There was a mean difference of six days between female and male birth dates based on prospective estimates (Fig. 3A; mean female and male birth dates were 30 May and 24 May, respectively). There was a mean difference of 4.6 days between female and male birth dates based on retrospective estimates (Fig. 3B; mean female and male birth dates were 31 May and 27 May, KolmogorovSmirnov two-sample test, $\chi^{2}=8.0, \mathrm{df}=2, P=0.02$ ). 
A

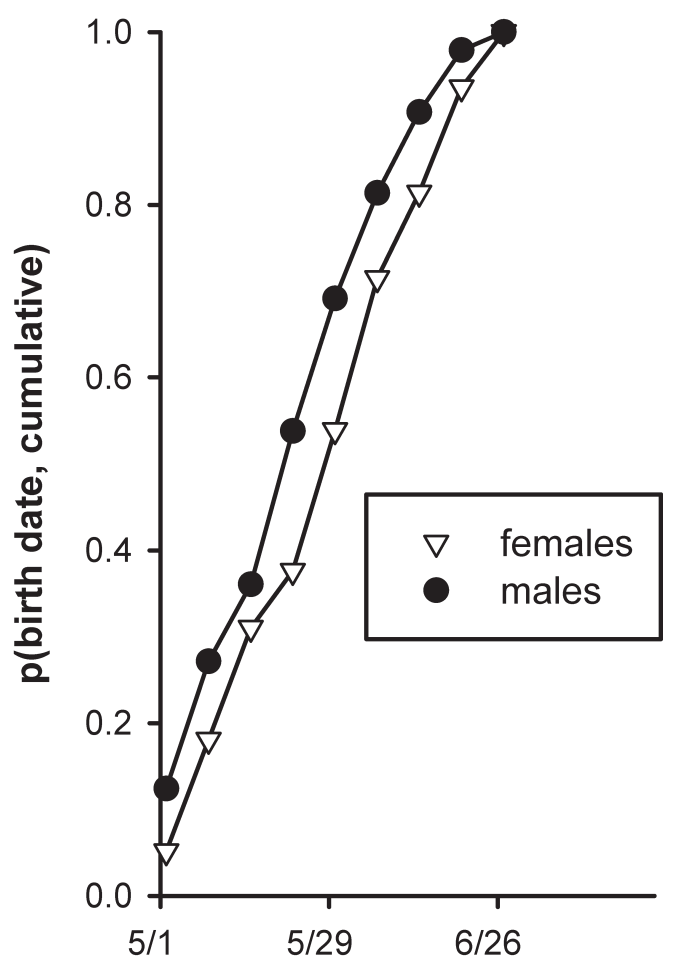

B

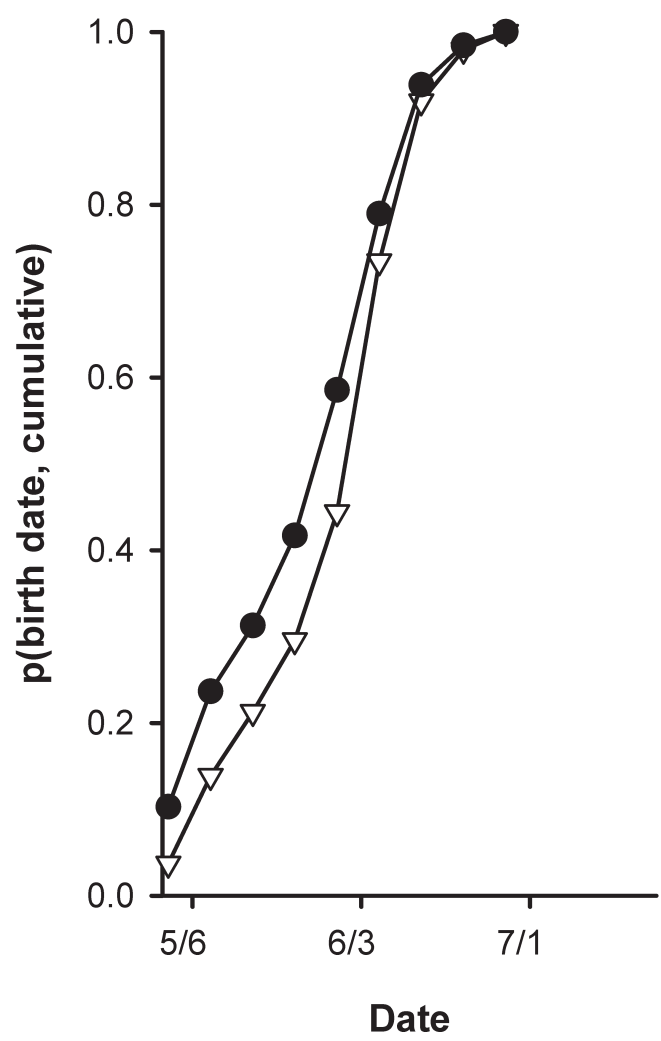

Fig. 3. Sex differences in birth-date distribution. Cumulative probability distributions representing the probability that birth date is less than or equal to the $X$-axis value are represented by sex. Birth date is divided into seven-day classes. (A) Prospective estimate from embryos. (B) Retrospective estimate from YOY.

\section{DISCUSSION}

This is the first case to my knowledge where PAT has been linked to a sex difference in the timing of birth. Protandrous arrival timing is familiar in migratory species, such that males arrive earlier at breeding grounds than females, and in arthropods that mate shortly after metamorphosis and eclosion. Conversely, a sex difference in the timing of birth is known to occur in vertebrates but is not associated with a sex difference in arrival at breeding sites. Only in the Dwarf Surfperch, with a uniquely derived life history, are the phenomena united.

The sex difference in the timing of birth arises from two distinct sex allocation patterns. One pattern is a sex difference in ontogeny-male birth is hastened relative to that of female siblings. The evidence for the sex difference in ontogeny was twofold: an apparent loss of males from parturient broods as the shortfall in embryos increased (i.e., as some individuals were born), and a difference between males and females in age at birth, as indicated by the daily age record. A second sex allocation pattern is a seasonal change in brood sex ratio, further shifting the distribution of male birth dates to earlier in the season than female birth dates. Although these two sex allocation patterns must occur via different proximate mechanisms, there may be a common ultimate explanation, involving male competition for access to receptive females. Following discussion of the sex allocation patterns, I turn to the selective environment that promotes them.

A sex difference in the timing of early life history transitions such as hatching or birth is rarely reported, and this is apparently the first such sex difference reported for fishes. The proximate mechanism by which early male birth is achieved is not known. Among birds, sex biases in laying and hatch order have been recorded for passerines and raptors (Bortolotti, 1986; Badyaev et al., 2002), but there is no evidence that time in the egg differs between male and female chicks. There is no evidence of a sex difference in hatching time of non-mammalian amniotes. Among mammals, humans are the only species for which a sex difference in gestational age is known; preterm births are more common among males than females (Cooperstock and Campbell, 1996; Ingemarsson, 2003), and there is a sex difference of a full day in the distribution of gestational ages of live births or total births (live births + still births, calculated from results in Joseph et al., 2005).

Seasonal changes in brood sex ratio are widely known and are typically associated with temperature-dependent sex determination (TSD). Temperature-dependent sex determination has not been demonstrated in the surfperches but is known to occur in related fishes, in other live-bearing fishes (Conover, 2004) and in other taxa (Valenzuela and Lance, 2004). Conditions are favorable to the evolution of TSD in the present case, assuming there are selective advantages. Temperature is a reliable cue for future birth date: seasonal variability in nearshore water temperatures in Tomales Bay is such that early and late broods differing by three months in timing would be exposed to a $7^{\circ} \mathrm{C}$ difference in temperature at each developmental stage (Schultz, 1990b), a contrast comparable to that reported in other studies of TSD in fishes (Conover, 2004). Therefore, temperature is a reliable cue at any time in development for the relative fitness of a male or female offspring. Further testing of TSD in Dwarf Perch would require experimental control of temperature prior to and during early pregnancy in a captive population. 
A sex difference in embryo mortality patterns is not likely to have caused the seasonal shift in sex ratio and apparent sex differences in development reported here. It is important to note that embryo mortality can be observed, because dead embryos are apparently retained and resorbed; embryos that are being digested are occasionally found, and the process may be advanced to the point where only compacted skeletal remains are seen. In Tomales Bay such embryo mortality is apparently rare: nine embryos were recorded as decayed and four as deformed, out of a total of 13,842 embryos examined in 1986. In contrast, in an urban estuary (Mission Bay, San Diego), some collections had many broods with decayed and deformed embryos (pers. obs.).

Maternal condition may also influence brood sex ratio, in addition to seasonal effects. Larger, older females with greater energy reserves breed earlier in the season than small young females (Schultz et al., 1991). Hence, mothers who are in good condition give birth to more males than females. Maternal condition is predicted to influence brood sex ratio when the benefits of high maternal condition accrue more to one sex than the other (Trivers and Willard, 1973). This theory's predictions are not completely confirmed in the Dwarf Perch case. One prediction that is confirmed is that older high-condition females had larger near-term embryos than younger females. A second prediction that is not confirmed is that the near-term embryo size effect of maternal condition should be greater in males than females. The size difference, if anything, is greater in female embryos than male embryos (Schultz, 1990b).

Sex-determination or sex-biasing mechanisms that respond to seasonal cues are selectively favored when seasonal factors differentially affect future reproductive prospects for males and females (Charnov and Bull, 1977; Werren and Charnov, 1978). Studies on vertebrates have demonstrated sex differences in the effect of birth date on fertility (Conover, 1984), age at maturity (Daan et al., 1996), and in mating success because of intrasexual selection (Wright et al., 1995; Smallwood and Smallwood, 1998). Similarly, a sex difference in the timing of arrival to breeding sites such as PAT should arise when the relationship between timing and reproductive success varies with sex. In a recent review, Morbey and Ydenberg (2001) identified seven distinct hypotheses that have been offered for PAT. A decisive analysis of these alternatives in Dwarf Perch is not presently possible, but the most likely can be identified and others can be rejected based on features of this species' mating system.

The most likely ultimate explanation for PAT in the Dwarf Perch is that it arises from exploitation (scramble) competition for copulations among recently-born YOY males (the mating opportunity hypothesis; Morbey and Ydenberg, 2001). Such competitive situations shift the optimal arrival (birth) date distribution for males to earlier than the female arrival date distribution (Bulmer, 1983; Iwasa et al., 1983; Parker and Courtney, 1983; Morbey, 2002). Features of the Dwarf Perch mating system indicate that scramble competition for access to females is an important determinant of newborn male reproductive success. Young-of-year males mate exclusively with YOY females, who are inseminated by multiple males shortly after birth (Warner and Harlan, 1982). Young-of-year males are not territorial (Warner and Harlan, 1982). Multiple paternity has not been documented in M. minimus but has been demonstrated in other surfperch species (Darling et al., 1980; Phelps et al., 1995), and the large testis size of YOY M. minimus males is suggestive of sperm competition (Warner and Harlan, 1982; Schultz, 1993a).

The mate opportunity hypothesis is one of four in which there is direct selection on a sex difference in timing; the other three are waiting cost, mate choice, and outbreeding (Morbey and Ydenberg, 2001). The waiting cost hypothesis posits that male physiology or behavior imposes a necessary delay between arrival and mating. There appears to be no such delay in Dwarf Perch, at least judging from the large testes and free production of sperm among neonates (Warner and Harlan, 1982; ETS, unpubl. data). The mate choice hypothesis suggests that females prefer males who have persisted the longest at the breeding site, hence favoring early arrival. Female preferences would appear to be relatively weak, given the high prevalence of multiple mating, large testis size, and the likelihood of multiple paternity (Warner and Harlan, 1982). Under the outbreeding hypothesis, sex difference in arrival reduces the probability of mating with siblings. This hypothesis is generally weak because it does not explain why males should arrive before females, and can be firmly rejected in the present case because females mate with males over a prolonged mating season.

Three other hypotheses that have been advanced to explain PAT suggest that differences in timing have arisen as correlated responses to direct selection on something other than the difference in timing per se (Morbey and Ydenberg, 2001). The rank advantage scenario applies to situations in which males arriving early acquire high-quality territories, and therefore does not apply to young-of-year Dwarf Perch. Under the susceptibility hypothesis, males are less vulnerable than females to adverse conditions early in the season, as might be the case if there is sexual size dimorphism. Even before birth, Dwarf Perch males grow more slowly and are smaller than females, and might be expected to be, if anything, more susceptible to early-season adversity. Finally, the constraint hypothesis refers to situations where there is a sex difference in selection on a trait that is similarly correlated with arrival timing in both sexes (i.e., the trait is constrained to covary with arrival timing). This hypothesis serves as a general alternative to any hypothesis of direct selection on sex differences in timing, and can be refuted by showing plasticity in the trait linkage. With regards to the Dwarf Perch, there is no evident candidate for such a linked trait, but the hypothesis cannot be ruled out.

The mate opportunity hypothesis is thus the strongest but not the sole possible explanation for PAT in Dwarf Perch, and should be comprehensively tested in this and other cases. Multiple approaches to testing are possible. One general approach is to measure male success as a function of arrival time, ideally in settings where arrival time can be experimentally controlled (Morbey, 2003). Unfortunately, the habitat of M. minimus (turbid and turbulent water) is not conducive to prolonged focal-animal observations that would be needed to estimate mating success of individuals with known birth dates (Warner and Harlan, 1982). Another general approach is to develop predictions of arrival time based on alternative selective scenarios. Game-theoretic models of arrival timing have demonstrated that PAT can arise as an evolutionary stable strategy for males engaged in competition for mates (Bulmer, 1983; Iwasa et al., 1983; Parker and Courtney, 1983; Morbey, 2002). Further application of these models in an effort to determine whether 
they successfully predict the degree of PAT in specific cases, and more accurately predict PAT than models based on other hypotheses, is needed.

\section{ACKNOWLEDGMENTS}

Field sampling was conducted with the help of many volunteer assistants, under California Scientific Collecting Permit 2003. C. Elphick provided helpful comments on manuscript drafts. Sources of support included a National Science Foundation Predoctoral fellowship, a University of California Special Regent's Fellowship, a University of California Graduate Research Grant, a Sigma Xi Grant-inAid, a grant from the American Museum of Natural History Lerner-Gray Fund, a California Institute for Marine Resources Dissertation Fellowship, and a grant from the American Behavior Society.

\section{LITERATURE CITED}

Badyaev, A. V., G. E. Hill, M. L. Beck, A. A. Dervan, R. A. Duckworth, K. J. Mcgraw, P. M. Nolan, and L. A. Whittingham. 2002. Sex-biased hatching order and adaptive population divergence in a passerine bird. Science 295:316-318.

Bortolotti, G. R. 1986. Influence of sibling competition on nestling sex ratios of sexually dimorphic birds. American Naturalist 127:495-507.

Bulmer, M. G. 1983. Models for the evolution of protandry in insects. Theoretical Population Biology 23:314-322.

Charnov, E. L., and J. Bull. 1977. When is sex environmentally determined? Nature 266:828-830.

Conover, D. O. 1984. Adaptive significance of temperaturedependent sex determination in a fish. American Naturalist 123:297-313.

Conover, D. O. 2004. Temperature-dependent sex determination in fishes, p. 11-20. In: Temperature-Dependent Sex Determination in Vertebrates. N. Valenzuela and V. Lance (eds.). Smithsonian Institution, Washington, D.C.

Cooperstock, M., and J. Campbell. 1996. Excess males in preterm birth: interactions with gestational age, race, and multiple birth. Obstetrics and Gynecology 88:189-193.

Daan, S., C. Dijkstra, and F. J. Weissing. 1996. An evolutionary explanation for seasonal trends in sex ratios. Behavioral Ecology 7:426-430.

Darling, J., M. Noble, and E. Shaw. 1980. Reproductive strategies in the surfperches. I. Multiple insemination in natural populations of the shiner perch, Cymatogaster aggregata. Evolution 34:271-277.

Dijkstra, C., S. Daan, and J. B. Buker. 1990. Adaptive seasonal variation in the sex ratio of kestrel broods. Functional Ecology 4:143-147.

Harlow, P. S., and J. E. Taylor. 2000. Reproductive ecology of the jacky dragon (Amphibolurus muricatus): an agamid lizard with temperature-dependent sex determination. Austral Ecology 25:640-652.

Hubbs, C. L. 1917. The breeding habits of the viviparous perch, Cymatogaster. Copeia 1917:72-74.

Hubbs, C. L. 1921. The ecology and life-history of Amphigonopterus aurora and of other viviparous perches of California. Biological Bulletin of the Marine Biological Laboratory, Woods Hole 60:181-209.

Ingemarsson, I. 2003. Gender aspects of preterm birth. BJOG: an International Journal of Obstetrics and Gynaecology 110:34-38.
Iwasa, Y., F. J. Odendaal, D. D. Murphy, P. R. Ehrlich, and A. E. Launer. 1983. Emergence patterns in butterflies: a hypothesis and a test. Theoretical Population Biology 23:363-379.

Joseph, K. S., R. Wilkins, L. Dodds, V. M. Allen, A. Ohlsson, S. Marcoux, and R. Liston. 2005. Customized birth weight for gestational age standards: perinatal mortality patterns are consistent with separate standards for males and females but not for blacks and whites. BMC Pregnancy and Childbirth 5.

Kokko, H. 1999. Competition for early arrival in migratory birds. Journal of Animal Ecology 68:940-950.

Morbey, Y. E. 2002. Protandry models and their application to salmon. Behavioral Ecology 13:337-343.

Morbey, Y. E. 2003. Pair formation, pre-spawning waiting, and protandry in kokanee, Oncorhynchus nerka. Behavioral Ecology and Sociobiology 54:127-135.

Morbey, Y. E., and R. C. Ydenberg. 2001. Protandrous arrival timing to breeding areas: a review. Ecology Letters 4:663-673.

Newman, M. C. 1993. Regression analysis of log-transformed data: statistical bias and its correction. Environmental Toxicology and Chemistry 12:1129-1133.

Parker, G. A., and S. P. Courtney. 1983. Seasonal incidence: adaptive variation in the timing of life history stages. Journal of Theoretical Biology 105:147-155.

Phelps, A., D. Bartley, and D. Hedgecock. 1995. Electrophoretic evidence for multiple mating in tule perch. California Fish and Game 81:147-154.

Schultz, E. T. 1990a. Daily otolith increments and the early life history of a viviparous fish, Micrometrus minimus. Copeia 1990:59-67.

Schultz, E. T. 1990b. Why do small dwarf perch breed late? The causes and consequences of breeding schedule variation in female Micrometrus minimus. Unpubl. Ph.D. diss., University of California, Santa Barbara.

Schultz, E. T. 1993a. Sexual size dimorphism at birth in Micrometrus minimus (Embiotocidae): a prenatal cost of reproduction. Copeia 1993:456-463.

Schultz, E. T. 1993b. The effect of birth date on fitness of female dwarf perch, Micrometrus minimus (Perciformes: Embiotocidae). Evolution 47:520-539.

Schultz, E. T., L. M. Clifton, and R. R. Warner. 1991. Energetic constraints and size-based tactics: the adaptive significance of breeding-schedule variation in a marine fish (Embiotocidae: Micrometrus minimus). American Naturalist 138:1408-1430.

Schultz, E. T., and P. C. Rountos. 2001. Analysis of daily growth patterns in young-of-year male dwarf surfperch (Embiotocidae: Micrometrus minimus) reveals alternative strategies: breed after birth or grow. Copeia 2001:14-24.

Siegel, S., and N. J. Castellan, Jr. 1988. Nonparametric Statistics for the Behavioral Sciences. McGraw-Hill, New York.

Smallwood, P. D., and J. A. Smallwood. 1998. Seasonal shifts in sex ratios of fledgling American kestrels (Falco sparverius paulus): the early bird hypothesis. Evolutionary Ecology 12:839-853.

Thornhill, R., and J. Alcock. 1983. The Evolution of Insect Mating Systems. Harvard University Press, Cambridge, Massachusetts.

Trivers, R. L., and D. E. Willard. 1973. Natural selection of parental ability to vary the sex ratio of offspring. Science 179:90-92. 
Valenzuela, N., and V. Lance (eds.). 2004. TemperatureDependent Sex Determination in Vertebrates. Smithsonian Books, Washington, D.C.

Warner, R. R., and R. K. Harlan. 1982. Sperm competition and sperm storage as determinants of sexual dimorphism in the dwarf surfperch, Micrometrus minimus. Evolution 36:44-55.

Werren, J. H., and E. L. Charnov. 1978. Facultative sex ratios and population dynamics. Nature 272:349-350.

Wright, D. D., J. T. Ryser, and R. A. Kiltie. 1995. Firstcohort advantage hypothesis: a new twist on facultative sex ratio adjustment. American Naturalist 145:133-145.

Appendix 1. Analysis of Birth-Date Distributions.

Prospective estimates of birth-date distribution were developed from preparturient broods, omitting parturient broods. This analysis was previously conducted for female offspring only (Schultz, 1993b). For each preparturient brood collected, birth dates of male and female embryos were projected assuming sex-specific age-at-birth, as estimated from analysis of YOY individuals (see Results). The birth-date distribution was then estimated from the relative abundance of different birth-date classes. The abundance of different birth-date classes was estimated from samples taken on different collection dates, so that each class was sampled at a comparable interval before birth; this meant that the entire set of preparturient broods had to be subsampled. The criteria used to subsample the broods in this way were provided in Schultz (1993b). From 469 preparturient broods that could be sexed, containing 3404 female embryos and 3458 male embryos, subsampling yielded 157 preparturient broods containing 1105 female embryos and 1122 male embryos. The abundance of each birth-date class was then estimated as the number of embryos in the class divided by the sampling effort $\left(\mathrm{m}^{2}\right.$ of habitat sampled on each of the collection dates, see Schultz, 1993b).

Retrospective estimates of birth-date distribution were developed from YOY that were two or three weeks old, collected from mid-May to late July, comprising 948 females
Table 2. Criteria and Adjustments for Retrospective Estimate of Male Birth Date Distribution. For each collection of YOY individuals, the age range criteria (in days) for inclusion in the estimate, the birth date range associated with the age range criteria, the number of aged males falling within the age range criterion $(n)$, and the proportion of the males sampled on that date that were actually aged (P).

\begin{tabular}{cllrc}
\hline Collection date & Age range & Birth dates & $n$ & P \\
\hline $5 / 11$ & 9 \& above & up to $5 / 2$ & 4 & 0.42 \\
$5 / 25$ & $7-22$ & $5 / 3-5 / 18$ & 84 & 0.99 \\
$6 / 12$ & $8-24$ & $5 / 19-6 / 4$ & 39 & 0.45 \\
$6 / 25$ & $7-20$ & $6 / 5-6 / 18$ & 47 & 0.23 \\
$7 / 24$ & up to 35 & $6 / 19$ \& after & 15 & 0.99
\end{tabular}

and 689 males. Here again, the abundance of different birthdate classes was estimated from samples taken on different collection dates, so that each class was sampled at a comparable interval after birth. On some collection dates, not all YOY were aged to the day. Individuals had been randomly sampled for age determination and the number of YOY in the birth-date class could be corrected for the proportion that was aged from that date. The abundance of each birth-date class was estimated as the number of YOY in the class divided by the sampling effort $\left(\mathrm{m}^{2}\right.$ of habitat sampled on each of the collection dates). Table 2 presents subsampling criteria and adjustments for male YOY; comparable values for females were provided in Schultz (1993b). The subsampling required for accurate estimates of relative birthdate class abundance yielded 215 females and 187 males.

Both estimates of birth-date distribution were subject to assumptions. The prospective estimate assumed that the sex difference in age at birth was correct and constant over the season. Because it assumed a sex difference in age at birth, I used it for estimating, but not testing the significance of, the sex difference in birth-date distribution. Both the prospective and retrospective estimates assumed that mortality rates of males and females were comparable and constant over the season. 